\title{
PATRIO PODER
}

- Quœ quidem omnia clare demonstrant "Romani et Patrii juris parentum in liberos - potestatem aliam atque aliam esse $\$$.

Mello Freire, Inst. L 2 T $4 \S 15$.

Nenhum instituto merece mais attenção dos reformadores do Direito, que o patrio poder. A alteração profunda que se vae fazendo no casamento, a multiplicação dos divorcios, são um primeiro motivo, para se pensar sériamente na sorte dos menores, aos quaes falta a atmosphera da casa de familia. Demais, os estudos das actuaes condições dos menores no lar; vão fazendo cahir aquelle preconceito de que a educação no seio da familia é sempre a melhor.

Já se reconheceo que ha um limite a essa regra. Tirar, em quaesquer casos, aos paes os filhos para os entregar á educação do Estado, é sem duvida um dos muitos sonhos irrealizaveis. Conservar porém a creança em um meio deleterio, por um fanatismo pelo patrio poder, tal qual nos foi legado pelo Direito Romano, é outro absurdo, contra o qual se devem levantar todas as pessoas sensatas. Ha um meio termo a que devemos chegar, podendo o patrio poder ser ampliado ou restringido, dentro de certos limites, tendo o jurisconsulto presentes as circumstancias da educação do povo, de seus costumes; de suas condições economicas, de sua cultura intellectual e outras.

O patrio poder assenta indubitavelmente na natureza, e, por isto, perdurará, resistindo a todas as tentativas contra sua existencia. Vejamos quaes os seos factores naturaes. 
A fraqueza do homem nos primeiros tempos da vida, o amparo insubstituivel da mãe, cuja affeição pela prole se manifesta até nas feras, o amor do pae, menos intenso, é certo, do que o materno, são partes para que renuncie o Estado á intervenção, ao menos durante a tenra infancia, na criação e educação dos seos membros. A propia Sparta, o sepulcro da vida de familia, segundo um elegante mestre, admittia que as creanças, até os 7 annos ficassem no lar domestico.

Em traços geraes, vejamos o que foi o patrio poder, de que tanto se orgulhavam os romanos, e que caracter tomou nos diversos povos modernos, afim de podermos determinar, qual o seu conceito no Direito patrio actual, e como deve o legislador moderno o considerar.

Gaio mostrava acreditar que o patrio poder era peculiar aos romanos (Inst. L $1, \S 55$ ). O orgulho que transpira de suas palavras, referindo-se a ésta supposta particularidade do Direito Romano, só se explica pelo desejo que tinham os cidadãos romanos de patentearem a extensão de seus poderes, ainda que sobre fracos, quaes erão os filhos, a mulher e os escravos.

Enganava-se porém Gaio: muitos outros povos tinhão o patrio poder dividamente regulamentado, e muitos semelhante ao romano. Natural é tal conformidade entre as leis de povos distanciados, e entre os quaes não havia communicações frequentes. Explica-se pela identidade das circumstancias em que se achavão.

Na Judea, o poder do pae parece ter sido sómente limitado em dois casos, a saber: não poder sacrificar $o$ filho a Moloch (Lev, c. 20, vs 2 a 5, Deut. c. 12 v. 31); não $\odot$ poder matar, sinão com intervenção das autoridades (Deut. c 21 vs 18 a 21 ).

Em Athenas, as leis de Solon prohibiam que o pae dispuzesse da vida e da liberdade de seos filhos, salvo o caso de deshonra da filha, que podia ser vendida co- 
mo escrava. Ao pae prodigo, podiam os filhos privar da administração dos bens.

Havia ainda na Grecia a abdicatio (de patria potestate c. 6), que, segundo Cuq, não deve ser confundida com a romana, que consistia em "familia abjicere" (Cuq v. 1 p. 46 n. ${ }^{a} 9-2 . .^{2}$ ed).

Costuma-se dizer que, em Sparta, não havia patrio poder. Pelas leis de Lycurgo eram os recemnascidos defeituosos atirados a um abysmo, e os perfeitos tinham sua subsistencia assegurada pelo Estado. Decidia da sorte dessas creanças a assemblea dos antigos. Depois disso porém, assegurado ao novo espartano o direito de tomar parte no banquete da vida, ficava elle, até os 7 annos, aos cuidados dos paes. Não se póde pois dizer que em Sparta não havia patrio poder.

Em Roma tambem vemos a potestas vitoe et necis restringida e regulamentada, desde o tempo de Romulo (Cuq p. 46 n. ${ }^{\mathrm{a}}{ }^{1} .^{\mathrm{a}}$ ), do mesmo modo que o foi no Japão, na China e entre os Asciantes, na Cafraria (Post-Jur. Ethn. v. 1 p. 152 n. $^{a}$ 5).

A venda dos filhos perdurou em. Roma até depois de estabelecido o christianismo. Assim devia ser, porque tinha origem na miseria.

Diz Paulo que se fazia "contemplatione extremœ necessitatis, aut alimentorum gratiæ „. Constantino ainda a autorizava "propter nimiam paupertatem egestatemque victus „.

O que foi o patrio poder nos demais povos primitivos, ou melhor o que foi o poder do chefe de familia nos tempos primitivos, vê-se em Hermann Post (Jur. Ethn. v. $1 \S \S 44$ e segs.). Causa horror lembrar que contra entes fracos tanta atrocidade se desenvolvesse.

Tornando ao Direito Romano, vejamos como influiu elle nos romanistas modernos, de modo a infiltrar o seo espirito nas leis que nos regem. 
Vendo a instituição, distanciados do logar, do tempo e das ideas em que ella se gerou, apreciaram os romanistas mais notaveis com certa imparcialidade 0 patrio poder romano.

Voecio, por exemplo, depois de caracterizar 'o patrio poder como nascido das justas nupcias, da legitimação ou da adopção, quer soubesse, quer não o pae que a prole era sua, ainda quando pela loucura não o pudesse exercer ("etiam si furore vel amentia, aliove animi vitio laborantes, re ipsa non potuissent hanc potestatem exercere, ,), dá para isso uma explicação altamente romana, qual a tirada da const. 25 de nuptiis: "ne alias furoris infortunio calamitosis alia addatur in ademtione juris consistens afflictio». Seja dicto, de passagem, que este modo de julgar Voecio os doidos é bem diverso do de seu patricio o celebre Erasmo.

Com razão diz Voecio que o patrio poder é muito semelhante á propriedade (quasi proprietas), parecendome seguro que primitivamente não se distinguiam os dois institutos. A consequencia é que, diz o mestre, gerava as acções vindicatio liberorum ex jure quiritium, interdictum de liberis exhibendis, actio furti, utilis de sero corrupto, legis Aquilioe e outras semelhantes.

Mas já o sentimento de modernismo se apresenta quando o jct. diz que muitas dessas faculdades não eram peculiares ao patrio poder, tanto que competiam ás mães, e sobre os emancipados, accrescentando que a isto levava a razão natural: permissum sit naturali ratione. Parece-me que não se podia dar mais fundo golpe na instituição romana. Proclamar que o poder sobre os filhos é fundado na razão natural é, creio, abandonar por completo o Direito Romano, que o assenta na mesma base em que colloca o direito de propriedade.

Em Roma, respeitavam-se os poderes do chefe da familia sobre os filhos e sobre a propriedade, porque, 
como abaixo direi, era elle o verdadeiro membro da civitas, achava-se para com ésta na mesma relação em que nos tempos modernos o cidadão para com o Estado. A unidade da sociedade romana não era $\theta$ individuo, mas a familia, representada pelo paterfamilias. Nada pois de razão natural para legitimar o patrio poder romano: elle se funda só no respeito aos direitos do paterfamilias.

Tinha Voecio clara idéa de que já, a seu tempo, se achava em decadencia o patrio poder romano; e a prova é que affirma que, com excepção dos frisios, todos os povos haviam cerceado os direitos componentes do patrio poder, ou os attribuiram em parte á mãe. Aponta entre os effeitos supprimidos: a venda dos filhos, o usufructo do peculio adventicio e a substituição pupillar. Dentre os transferidos á mãe, refere a licença para as nupcias, quando falta o pae.

Não admitte Voecio que o avô tenha patrio poder, mostrando-se neste ponto mais adiantado que o legislador portuguez, que, embora, na O. L 4 T $87 \S 7$, proclamasse que os netos não estão sob o poder dos ascendentes, no L $4 \mathrm{~T} 102 \S 1$ attribue ao avô o direito de nomear em testamento tutor ao neto.

Quanto ao cerceamento dos direitos do pátrio poder, e á sua transferencia á mãe, oscillam os escriptores sobre o módo de explicar o facto. O mesmo Voecio ora diz que são direitos resultantes do patrio poder, ora os funda na natureza. A verdade, parece-me, é que o patrio poder, nos tempos primitivos, não passou de uma protecção legal ao chefe da familia; que este, movido, já pelo egoismo, já pela affeição natural, dispensava protecção aos filhos; que, melhoradas as condições da mulher, a ella foram attribuidos certos direitos sobre os filhos; e que, finalmente, comprehendendo as novas gerações que os fracos, mulheres e menores, mereciam amparo e assistencia da sociedade, cercearam 
muitos dos antigos direitos de chefe, que erão enfeixados no patrio poder, e attribuiram outros ás mães.

Realmente pois, si historicamente podemos dizer que certo direito não pertence ao patrio poder, porque compete á mãe, em face da doutrina, poderiamos sustentar, em sentido opposto, que a mãe tem fracções do patrio poder.

Parece-me que tão acertado andou Lobão falando no patrio poder que por Direito Natural têm as mães (Notas a Mello L 2 T $4 \S 6$ Rubr. pag. 76), quanto Schneidewinio, ao affirmar que não é effeito do patrio poder o que attribúe direitos á mãe, ou o que impõe direitos ao emancipado, como, por exemplo, o pedido de venia para a in jus vocatio (Inst. L 1 T 9 n. ${ }^{\circ} 30$ ).

Este ateve-se ao direito positivo, ao direito romano; aquelle, procurou o direito a constituir.

Não me refiro ao dec. 181, que, em dado caso (art. 94), attribue á mãe o exercicio pleno do patrio poder. Refiro-me, sim, á doutrina anterior, tracto dos romanistas do tempo das nossas Ordenações.

Dessas duas correntes, a historica e a racional, a positiva e a de direito ideal, o resultado foi surgir uma accentuada ambiguidade no direito actual. Vêmse os jurisconsultos na difficuldade de harmonizarem o que se constituiu em Roma, no só beneficio do chefe da familia, com o que indica a sciencia moderna, que é a protecção aos fracos, utilizando-se a sociedade das forças naturaes, entre as quaes se acham o egoismo e as affeições altruisticas.

Nas diversas nações em que influiu o direito romano, sente-se, nas leis, a dupla tendencia para servir ao interesse do pae, ou ao do filho.

Diz Planiol que no Sul da França foi conservada, ao menos com seu espirito geral, a antiga patria potestas do Direito Romano; mas que as provincias costumeiras tinham tradições muito differentes : a idéa duma 
proteç̧âo devida ao filho nellas dominava a organização do patrio poder (V 1 ns. 1637 e 1638).

Windscheid sustenta que só no direito romano originario apparecia o patrio poder como puramente egoistico, e instituido só em proveito do pae.

Este não era, diz elle, o conceito do direito justinianeo. Entretanto reconhece que, quer no direito justinianeo, quer no moderno, apparecem traços da rudeza primitiva ( $\$ 513)$.

O que observava Wịdscheid no Direito Allemão, é o que vemos no de todos os povos cultos: um mixto de romanismo correspondente a uma epocha, cujas necessidades tinham sido modificadas profundamente pela acção do tempo, e de idéas novas que irrompiam atravéz os textos das leis antigas.

Um simples exame summário do que era entre nós o patrio poder tornará bem patente isto.

Lafayette que sustenta que o nosso patrio poder era genuinamente romano, e constituia um invento absurdo, accrescenta que foi «imaginado antes em vantagem e utilidade do pae do que em beneficio do filho" $\S 112$, pag. $221 \mathrm{n}^{\circ} 1$ ). E' isto reconhecer que o beneficio do filho não ficava em completo esquecimento.

Não é no numero, ou na natureza dos direitos do pae sobre a pessoa do filho que está a maior ou menor aspereza do patrio poder, mas no modo por que são regulados esses direitos.

Assim póde haver extensão repugnante na faculdade de castigar, na do consentir no casamento e na de exigir serviços. Entre o direito dos tempos barbaros de matar o filho e o de o castigar moderadamente, vae um abysmo. Nos tempos antigos, o poder do pae não encontrava diante de si, como nos mais recentes, o do Estado, que tem por missão proteger os membros da sociedade que são mais fracos. A ésta linha de separação entre o poder do pae e o do Estado falta nitidez. 
Poderemos mesmo accrescentar que é ella oscillante, segundo a modificação das idéas.

Para exemplo de quão amorpho é este ponto de separação entre poderes do pae e do Estado citaremos a faculdade que, no Direito Francez, tem o pae de castigar o filho por meio da prisão, já por via de autoridade, já pela requisição (Baudry - Lacantinerie V..1 ns. 943 e 944). Ora tem o pae, em dadas circumstancias, a faculdade de exigir da autoridade a prisão do proprio filho; ora, havendo falta de certos requisitos, póde sómente expor á autoridade o que acha de irregular no procedimento do filho, pedindo-lhe que, conhecendo da accusação, resolva punil-o com a prisão.

As leis actuaes, perdido como se acha o fanatismo pelo Direito Romano, já não se embaraçam para darem profundos golpes na instituição do patrio poder, tirandolhe quanto tinha de repugnante para as nossas idéas. Neste sentido alguma cousa se tem feito, entre os povos cultos. A legislação patria bem pouco tem sido modificada neste ponto. Lembrarei, como exemplo do nosso pouco zelo sobre tal materia, a difficuldade que ha para cassar o patrio poder quando delle se mostra indigno o pae.

Contra este estado de coisas clamava Demolombe, no principio do seculo passado (De l'Adoption n. ${ }^{\circ} 367$ ).

No nosso Direito, as leis, com pequenas modificações, têm conservado o cunho do Direito Romano. Aos costumes devemos as profundas reformas nas relações entre paes e filhos. O proprio dec. 181 pouco modificou o estado da nossa legislação sobre o patrio poder. Em resumo: nossas leis, mantendo em seos traços geraes o Direito Romano, e modificando-o em poucos pontos, sob a influencia das idéas modernas; o nosso direito costumeiro exercendo mais profunda influencia no systema do Direito Patrio, relativamente a esse instituto juridico. 
Mas vejamos quaes as bases em que devemos hoje assentar o patrio poder. Estamos numa epoca de reformas, e nem o direito de familia escapa aos fortes e penetrantes golpes da picareta do progresso.

E' sabido que certa escola socialista pretende extinguir o patrio poder, attribuindo ao Estado todos os direitos que até hoje cabiam ao chefe da familia. E' querer o impossivel. E' ir de encontro ás leis da natureza. Com tal systema, aliás irrealizavel, impraticavel, chegariamos a inconvenientes tão graves, quanto o eram os gerados pelo antigo patrio poder romano dos tempos primitivos.

O instituto deve ser fundado na natureza do homem, e nas condiçôes sociaes. Consenquentemente, terá o legislador de aproveitar quanto a natureza poz á sua disposição: o amor materno que se manifesta, ao menos nos primeiros tempos, em elevadissimo grau de intensidade; $a$ affeição ou amizade gerada pela vida em familia, e a nascida dos laços de sangue; os sentimentos de benevolencia para com os entes fracos collocados sob nossa protecção, sentimentos que, si não são fructo da vida em sociedade, como pensam alguns escriptores, são pela vida social desenvolvidos, aperfeiçoados, acrisolados; certo amor proprio, que leva os chefes da familia a verem nas qualidades dos descendentes suas proprias virtudes, julgando que renascem na prole; emfim outros elementos menos importantes, mas que não devem ser desprezados pelo legislador. Estes são os anthropologicos motivos para confiar aos chefes da familia o poder sobre os menores. Ha ainda factores sociaes: a opinião pública, que condemna qualquer tyrannia, ou brutalidade contra os entes fracos; o estado de cultura moral relativamente adiantado dos actuaes chefes de familia etc.

Por outro lado porém, podemos contar com fortissimos motivos para restricções do patrio poder attri- 


\section{$-76-$}

buido aos chefes de familia. O que acabo de referir é o que geralmente succede, mas a lei que prevê o "quod plerumque fit», não póde deixar em esquecimento os casos raros, mas gravissimos, quaes os de máus tratos aos filhos, exemplos pervertedores, corrupção e até incesto :

Não se fundando mais o patrio poder no interesse do chefe, poderá o Estado cortar profundamente nos direitos do chefe da familia.

E' bom fazermos, aqui, uma comparação entre 0 fundamento do patrio poder romano e o actual, como é indicado pelo Direito Natural, dando a razão historica da differença entre ambos. A civitas, como acima dissemos, quando se constituio, já achou a familia organizada. A unidade, o elemento ultimo della, não era, como o é no Estado moderno, o individuo, mas a familia. O Direito Romano era o direito dos patres familias, e não o dos individuos. A civitas nada mais fez do que cercear gradativamente a potestas do paterfamilias: não lhe concedeu um jus. (Cuq V 1 p. 45 n. ${ }^{\circ}$ 4). O que se deu em Roma, foi mais ou menos o que occorreu nos demais povos, passando o instituto pelas mesmas phases evolutivas.

Mas, constituido o Estado moderno, desapparecidos os principios antigos que regiam a patria patestas, mudadas as condições sociaes, já não tem o legislador actualmente nenhum motivo de contemplação pelos direitos do chefe de familia. Para a lei actual, o menor e o chefe estão no mesmo pé de egualdade. Cumpre ao nosso legislador attender exclusivamente ás condições de desenvolvimento dos individuos, membros dá sociedade, e ás da propria sociedade - feliz conservação e rapido desenvolvimento, a adoptarmos a fórmula seguida pelos escriptores italianos.

Em uma palavra: o Estado moderno póde, inspirando-se no interesse dos individuos e da sociedade, 
regulamentar a autoridade do chefe de familia no sentido de melhor salvaguardar taes interesses. Si o Estado não deve exercer por si o patrio poder, é porque é improprio para tal ministerio, e esse exercicio sería grandemente prejudicial aos individuos e á sociedade.

Esta é, creio, a verdadeira concepção positiva da instituição do patrio poder.

Fundando-o em factores anthropologicos e sociaes, attendendo ás necessidades do individuo e da communhão social, teremos uma instituição conforme aos ideaes juridicos da nossa sociedade.

Um pouco afasto-me do egregio mestre Puglia. Diz elle: "O patrio poder não é mais o poder illimitado do pae de familia sobre a prole, não é estabelecido no interesse daquelle, mas no das pessoas sobre que cahe."

Não: o patrio poder é instituido não só no interesse dos menores, mas no dos paes de familia, e no da sociedade em geral. Si o que, á primeira vista, mais attrahe a attenção do legislador é o interesse do menor, não menos justo é que attenda aos dos paes, compensando-os dos sacrificios que fizeram pelos filhos. Esta compensação lhes é devida, porque tambem são membros da sociedade, e merecem della auxilio.

Considerada a instituição do ponto de vista politico, claro é que quasi toda a habilidade do legislador consistirá em pôr em acção, em beneficio da sociedade, os multiplos motores egoisticos, e os raros altruisticos dos paes e dos filhos. Assim, por exemplo, privar os filhos de certas vantagens na herança dos paes, e a estes de outras sobre os bens dos filhos, são penas vantajosas para garantirem no seio da familia o cumprimento dos deveres reciprocos entre paes e filhos.

Grandemente importante é uma boa regulamentação do patrio poder. Sabido é hoje quanta importancia tem a educação das crianças na sorte da sociedade. A boa educação não só diminue os crimes, mas tambem 
fórma um povo amante do progresso, respeitador do Direito e da Moral, e consequentemente gera o bem estar social. A corrupção do lar domestico, a falta de educação e de instrucção aos moços, são os mais tristes factores do atrazo de um povo e do augmento da criminalidade. Para mostrar quanto inflúe nas crianças $o$ máu exemplo dado pelos paes, lembrarei o que dizem alguns penalistas ao intento de provarem que mais influem no caracter os factores sociaes do que os anthropologicos, mais o meio, do que a herança, mais uma boa atmosphera moral, do que uma boa constituição natural. Dizem os penalistas que muito mais frequentemente achamos familias de ladrões do que de assassinos.

Dahi se póde inferir quanto cuidado deve ter o poder publico em zelar a educação da infancia, fiscalizando o procedimento dos chefes de familia, e, em circumstancias extremas, arrancando-lhes das mãos os filhos.

Ninguem contesta que ha grande difficuldade em reformar a instituição, guardando um justo e prudente meio entre o respeito excessivo aos interesses do pae, e o exaggerado fanatismo pela necessidade social. Ninguem contesta que muitas medidas ideadas pelo legislador darão resultados diversos, quiçá oppostos dos por elle collimados. Ninguem porém tambem contestará que é das mais difficeis a arte de legislar, e que portanto não são extranhaveis essas más consequencias possiveis

JoÃo ARRUda. 